\title{
A Rapid Procedure for the Determination of C60 and C70 Fullerenes in Soil and Sediments by Ultrasound-assisted Extraction and HPLC-UV
}

\author{
Rosa Ana Pérez, Beatriz Albero, Esther Miguel, José Luis Tadeo, and \\ Consuelo SÁNCHEZ-BRUNETE ${ }^{\dagger}$
}

Departamento de Medio Ambiente, INIA, Ctra de la Coruña, 7, 28040 Madrid, Spain

\begin{abstract}
In this work, a rapid and sensitive method, based on ultrasound-assisted extraction of samples with a small volume of toluene, has been developed for the quantification of C60 and C70 fullerenes in soil and sediments. Good extraction efficiencies were obtained at all of the fortification levels studied (200, 100, 20 and $2 \mathrm{ng} / \mathrm{g}$ ), which ranged from 72 to 104\%. An important effect of the extraction temperature was observed on C60 recoveries, and an acceptable decrease in the recovery rates was observed in aged samples. In the case of wet samples, the extraction can be done by percolating a small volume of acetonitrile before extraction. The extraction yields of the developed method for the extraction of C60 and C70 from soil were compared with those obtained by pressurized liquid extraction. Finally, analyses of fullerenes in agricultural and industrial soils and sediments were carried out, but no fullerene residues were found.
\end{abstract}

(Received October 15, 2012; Accepted March 6, 2013; Published May 10, 2013)

\section{Introduction}

As a result of the ongoing advances in nanotechnology and the increasing use and production of engineered nanoparticles (ENPs) for different purposes, the release of substantial amounts of ENPs into the environment is growing, and it is expected to increase considerably in the future. Fullerenes are carbonaceous nanoparticles made entirely of carbon that may contain pentagonal and hexagonal rings, being C60 (an icosahedral structure) the most common form and $\mathrm{C} 70$, with an oblong form, the next stable fullerene. ${ }^{1,2}$ Fullerenes have been detected at very low concentrations in geological materials and in a wide range of extraterrestrial materials $;^{3}$ therefore, the natural presence of fullerenes has been related to materials affected by high-energy events. ${ }^{4}$ The use of these compounds in a great variety of commercial products and in many biomedical and industrial applications is expected to be due to their optical and electrochemical features, as well as to other properties, such as, their high strength and radical scavenging capability. ${ }^{5}$ As a result of the growing industrial applications and increasing household usage of fullerenes, there is rising interest regarding their presence, behavior and effects in the environment. ${ }^{1,2,4-7}$ Although $\mathrm{C} 60$ is the main fullerene studied as an emerging contaminant, ${ }^{8}$ Sanchís et al. ${ }^{6}$ found that C70 was the most frequently detected fullerene in airborne particulate matter from the Mediterranean Sea. In general for ENPs, and particularly for fullerenes, it is necessary to develop or improve the methodology for their detection and quantification in different environmental matrices. Thus, in a critical review, Isaacson et al. ${ }^{4}$ pointed out that many reports had been published on the

$\dagger$ To whom correspondence should be addressed.

E-mail: palop@inia.es synthesis and application of fullerene materials, but quantitative information describing the occurrence, behavior, and transport of fullerenes is still lacking.

Soxhlet extraction and ultrasonic assisted extraction (UAE) are the procedures most commonly used to extract fullerenes from environmental samples; ;,6,9 although for solid samples, extraction methods such as shaking ${ }^{10}$ and pressurized liquid extraction (PLE) 3,11 have been reported, too. In general, the methods described above used large amounts of organic solvent in the extractive process.

Although fullerenes show a poor solubility in most organic solvents, some aromatic solvents and carbon disulfide, among others, are commonly used. ${ }^{12-14}$ Nowadays, toluene is the most widely used solvent for the solution and extraction of fullerenes, and was employed in the extraction methods reported above.

Most analytical methods use liquid chromatography (HPLC), combined with ultraviolet-visible detection (UV) or mass spectrometry (MS) for the detection of fullerenes in geological, environmental or biological samples. ${ }^{4,7}$ In order to achieve high selectivity and sensitivity in the quantitative analysis of fullerenes in environmental samples, HPLC-MS and tandem MS have been recently applied in the determination of fullerenes in water and suspended material of wastewater effluents, ${ }^{15}$ in rat tissues and blood ${ }^{16}$ or in aerosol samples. ${ }^{6}$

Although the separation of C60 and C70 can be carried out with various stationary phases,${ }^{12}$ most of the studies available in the literature were performed by the separation of these compounds using C18 columns, or columns that had specifically designed ligands for fullerene separation. ${ }^{16-19}$ Despite their good separation properties and capacity to retain fullerenes with a $100 \%$ toluene mobile phase, the main drawback of these specifically designed columns is their high price in comparison to a $\mathrm{C} 18$ column. Thus, an increase in the use of a C18 column for fullerenes analysis has been observed. ${ }^{6,11,20,21}$ 
The extraction of fullerenes from solid environmental matrices, such as soil or sediments, has been scarcely reported due to their complexity. Shareef et al. ${ }^{11}$ reported an analytical method for the determination of C60 in soil using PLE followed by HPLC-UV. The main drawbacks of this method were that only one fullerene was evaluated, and the relatively high limit of detection (LOD) achieved $(20 \mu \mathrm{g} / \mathrm{kg})$. In a recent publication, Wang et al. ${ }^{5}$ used an artificial sediment to develop an analytical method to quantify C60 using HPLC-UV, where the extraction was carried out by shaking using a high solvent volume $(40 \mathrm{~mL})$, and a high limit of quantification (LOQ) was reported for C60 $(0.15 \mathrm{mg} / \mathrm{kg})$ with this methodology. To the best of our knowledge, these are the only methods reported for the determination of fullerenes (C60 only) in soil and sediments.

In this context, the main objective of our study was to develop a fast and sensitive method for the analysis of C60 and C70 in soil and sediments by UAE, using a low volume of extraction solvent and without the need of sophisticated extraction instrumentation. The effects of the extraction temperature and time, soil moisture and the residence time of residues in soil on the recoveries of both compounds by UAE were studied. For comparative purposes, PLE was applied for the extraction of C60 and C70 from soil samples, and both methods were compared. Finally, the UAE method was applied to the analysis of C60 and C70 fullerenes in soil and sediment samples collected in different areas of Spain. As far as we know, this is the first reported method for the simultaneous determinations of C60 and C70 in soil and sediment by a fast and miniaturized extraction method.

\section{Experimental}

\section{Reagents and chemicals}

Toluene and propan-2-ol, HPLC grade, were purchased from Lab Scan, Analytical Science (Poland). Acetonitrile (ACN) gradient $240 \mathrm{~nm} /$ far UV, HPLC grade and $n$-hexane, residue analysis grade, were obtained from Scharlab (Barcelona, Spain). Fat-free quartz sand was supplied by Buchi AG (Switzerland). LabortechnikFullerene-C60 (99.5\%) and [5,6]-fullerene-C70 (99\%) were supplied by Sigma-Aldrich (Steinheim, Germany). Separate stock solutions of individual compounds were made up at $500 \mu \mathrm{g} / \mathrm{mL}$ in toluene. A working standard mixture containing $5 \mu \mathrm{g} / \mathrm{mL}$ of the individual compounds was prepared by dilution of the stock solutions in toluene. This working standard mixture was used to prepare adequate spiking solutions or calibration standards. All of the solutions were stored at $4{ }^{\circ} \mathrm{C}$ prior to use.

\section{Apparatus}

All measurements were performed using a 1100 HPLC instrument equipped with gradient pump, autosampler and programmable UV detector from Agilent Technologies (Wilmington, DE). The chromatographic separation was carried out in a Luna $5 \mu \mathrm{m} \mathrm{C18}$ (2) 100 A HPLC column $(150 \times$ $4.60 \mathrm{~mm}$ ) from Phenomenex (Torrance, CA).

HPLC separations were performed by injecting $100 \mu \mathrm{L}$ with an isocratic toluene $(60 \%)$ and $\mathrm{ACN}(40 \%)$ mobile phase at a flow rate of $0.75 \mathrm{~mL} / \mathrm{min}$. The UV detector was programmed at $334 \mathrm{~nm}$ for the detection of C60 and C70 fullerenes. The total analysis time was $10 \mathrm{~min}$.

\section{Samples collection}

Soil used in the recovery assays was collected from the plough layer $(0-10 \mathrm{~cm})$ of an experimental plot located in the region of Madrid (Spain), sieved $(2 \mathrm{~mm})$, and stored at room temperature until spiked. The characteristics of the soil were: $\mathrm{pH} 7.7$, moisture content $1 \%$, total organic matter content $0.97 \%$, sand $44.34 \%$, silt $37.44 \%$ and clay $18.22 \%$. Surface soil from agricultural fields (horticultural and forested) located in different Spanish regions and industrial soils from the area of Bilbao, an important industrial region, were sampled, air dried, sieved and stored frozen $\left(-18^{\circ} \mathrm{C}\right)$ in glass containers until their evaluation.

Sediments were obtained from different rivers of Madrid (Manzanares, Jarama, Henares, Guadarrama and Lozoya). Sediments were collected into glass containers, previously rinsed several times with acetone, and stored refrigerated during transport to the laboratory. Before analysis, sediments were dried at room temperature, sieved and kept frozen at $-18^{\circ} \mathrm{C}$.

\section{Extraction procedures}

UAE method. Sieved soil or sediment $(5 \mathrm{~g} \pm 0.001)$ were weighed into a $10 \mathrm{~mL}$ weighing funnel and placed in a glass column $(20 \mathrm{~mL}), 10 \mathrm{~cm} \times 20 \mathrm{~mm}$ i.d. (Normax, Portugal), with a polyethylene frit of $2 \mathrm{~cm}$ diameter and $20 \mu \mathrm{m}$ pore size (Supelco, Madrid, Spain) at the end. Luer tips of the columns were closed with 1-way stopcocks. For recovery studies, soil samples were previously spiked with a mixture of fullerenes to reach final concentrations of 200,100, 20 and $2 \mathrm{ng} / \mathrm{g}$, whereas sediment samples were spiked with fullerenes at 20 and $2 \mathrm{ng} / \mathrm{g}$. Then, they were covered with aluminum foil and left in dark conditions at room temperature for $24 \mathrm{~h}$ to allow solvent evaporation. The samples were protected from light during the whole extraction procedure. Extractions were carried out with an ultrasonic water bath (Raypa, Barcelona, Spain) at room temperature, where water level was adjusted to equal the extraction solvent level inside the columns. Samples were extracted with $4 \mathrm{~mL}$ of toluene in an ultrasonic water bath (15 min). Then the columns were placed on a multiport vacuum manifold (Supelco, Visiprep, Madrid, Spain) where the solvent was collected in $10 \mathrm{~mL}$ graduated tubes. Another $4 \mathrm{~mL}$ of toluene were added to the samples that were sonicated again for $15 \mathrm{~min}$. The solvent was filtered and samples were washed with $1.5 \mathrm{~mL}$ of additional solvent. The combined extracts were concentrated to $1 \mathrm{~mL}$ using an evaporator Genevac EZ-2 (purchased from NET Interlab, S.A.L., Spain) and $1 \mathrm{~mL}$ of ACN was added to the tube to obtain a final extract in toluene:ACN $(50: 50, v / v)$. Finally, an aliquot of the extract was placed in an amber vial and analyzed by HPLC-UV.

PLE method. A metal frit and a cellulose disk were placed on the bottom of each extraction cell that was filled with $5 \mathrm{~g}$ amount of sieved soil sample and $25 \mathrm{~g}$ of sand, previously mixed in a mortar. Soil samples were extracted with a Speed Extractor E-916 (PLE system) (Buchi Labortechnik AG, Switzerland) furnished with $20 \mathrm{~mL}$ stainless-steel cells. For recovery studies, samples were previously spiked with fullerenes at 20 and $2 \mathrm{ng} / \mathrm{g}$ and left in dark conditions at room temperature for $24 \mathrm{~h}$ to allow solvent evaporation. The samples were protected from light during the whole extraction procedure. Toluene was used as extraction solvent, at a pressure of $140 \mathrm{bar}$ and temperatures of $30,60,90$ and $120^{\circ} \mathrm{C}$. Two extraction cycles were performed with heat-up, hold and discharge times of 1,8 and 2 min, respectively. Extracts were collected in $60 \mathrm{~mL}$ collection vials, pre-concentrated in a Multivapor P-12 equipped with a vacuum pump V-700 and a controller V-855 (Buchi Labortechnik AG, Switzerland) and transferred to $10 \mathrm{~mL}$ graduated tubes where they were concentrated to $1 \mathrm{~mL}$ using an evaporator Genevac EZ-2. Finally, $1 \mathrm{~mL}$ of ACN was added into the tube to obtain the final extract, which was analyzed by HPLC-UV. 


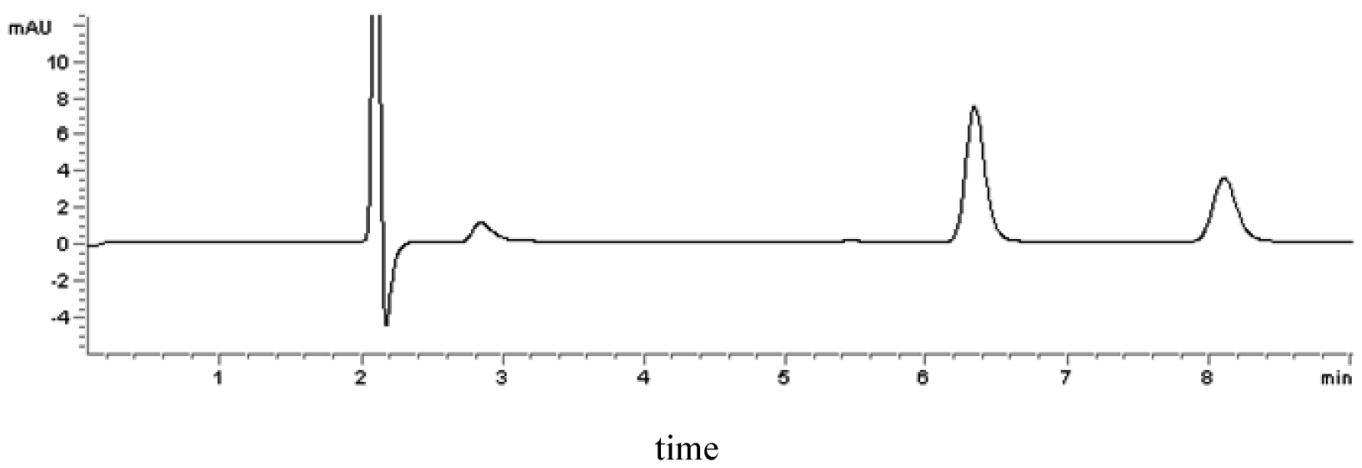

Fig. 1 Chromatogram of a C60 ( $\left.t_{\mathrm{r}}: 6.4 \mathrm{~min}\right)$ and $\mathrm{C} 70\left(t_{\mathrm{r}}: 8.2 \mathrm{~min}\right)$ mixture $(0.5 \mu \mathrm{g} / \mathrm{mL})$ obtained at $334 \mathrm{~nm}$ with an isocratic mobile phase composed of toluene:ACN $(60: 40, \mathrm{v} / \mathrm{v})$ at a flow rate of $0.75 \mathrm{~mL} / \mathrm{min}$.

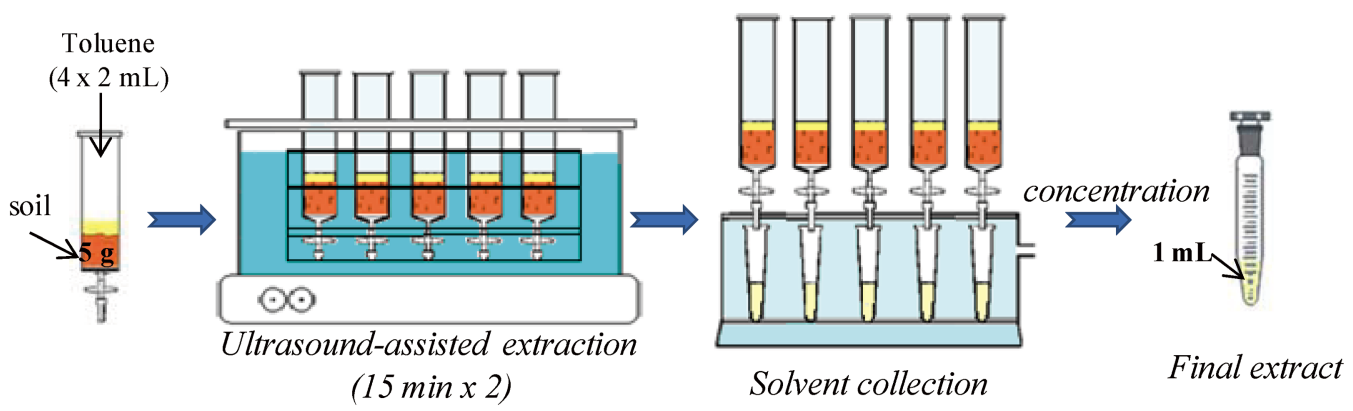

Fig. 2 Scheme of the UAE method.

Quality assurance and quality control

The quality assurance and control criteria used for this method included analyses of laboratory blanks (solvent blanks). Using the proposed procedures, background levels of laboratory blanks were below the detection limits. With each set of samples to be analyzed, a standard mixture and a laboratory blank were run in sequence to check for contamination, peak identification and quantification. LOQs were defined as the minimum amount of the target analyte that produces a peak with a signal-to-noise ratio of 10-times the baseline noise; they were determined using blank soil or sediment extracts obtained with the UAE method.

The concentration of each compound was determined by comparing peak areas obtained in samples with those found for standard mixtures of known concentration. The linear range was established by a nine point calibration curve $(2.5,5,12.5$, $25,50,250,500,750,1000 \mu \mathrm{g} / \mathrm{L})$.

\section{Statistical analysis}

Data was processed using Statgraphics plus version 5.0. One-way ANOVA was used for the determination of significant differences at a significance level of $p=0.05$.

\section{Results and Discussion}

\section{HPLC analysis}

The effect of the solvents used as mobile phase, as well as the flow rate employed in the chromatographic separation of C60 and C70 fullerenes were evaluated. A gradient elution method described by Shareef et al. ${ }^{11}$ was assayed as the starting point; however, C60 and C70 fullerenes signals could not be completely separated at any of the flow rates tested (from 0.7 to $1.5 \mathrm{~mL} / \mathrm{min}$ ). Additionally, a mixture hexane:isopropanol was assayed using different solvent proportions and flow rates, but broad and split peaks were always observed.

Taking into account recent papers on the analysis of fullerenes in water or in commercial cosmetics, ${ }^{17,21}$ an isocratic method with a mobile phase of toluene:ACN $(60: 40, \mathrm{v} / \mathrm{v})$ was evaluated. Although a good peak separation was observed, the injection of the samples in toluene gave slightly split peaks that were avoided diluting the toluene extract with the same quantity of $\mathrm{ACN}$ before the chromatographic analysis. In order to evaluate the effect of the flow rate on the retention time and chromatographic response, flow rates from 1.7 to $0.5 \mathrm{~mL} / \mathrm{min}$ were assayed. It was observed that high flow rates allowed sufficient peak separations, but decreased the chromatographic response. Finally, a flow rate of $0.75 \mathrm{~mL} / \mathrm{min}$ of a mixture toluene:ACN $(60: 40, \mathrm{v} / \mathrm{v})$ was selected for further analyses. Figure 1 shows the chromatogram obtained for a C60 and C70 mixture with this method.

\section{UAE optimization}

The selective extraction of analytes from complex matrices, such as soil and sediments, is a very complicated task, because these matrices contain a large variety of compounds that may hinder their analysis. The methods reported for fullerene analysis in different matrices use large amounts of toluene in the extractive process (from 25 to $100 \mathrm{~mL}$ ). . $^{3,69-11}$ UAE on small columns was selected, based on our experience with this technique, ${ }^{22}$ in order to miniaturize the extraction procedure. In this procedure, a low volume of extractive solvent $(9.5 \mathrm{~mL}$ in total) was used. Figure 2 shows a scheme of the proposed UAE 
Table 1 Effect of the temperature in the recoveries $(\% \pm \mathrm{SD})$ of $\mathrm{C} 60$ and $\mathrm{C} 70(2 \mathrm{ng} / \mathrm{g})$ from soil by UAE

\begin{tabular}{ccc}
\hline \multirow{2}{*}{ Compound } & \multicolumn{2}{c}{ Temperature } \\
\cline { 2 - 3 } & $22^{\circ} \mathrm{C}$ & $37^{\circ} \mathrm{C}$ \\
\hline $\mathrm{C} 60$ & $83.2 \pm 8.6$ & $36.7 \pm 5.5$ \\
$\mathrm{C} 70$ & $77.9 \pm 8.9$ & $68.1 \pm 3.7$ \\
\hline
\end{tabular}

a. Number of replicates, $n=3$.

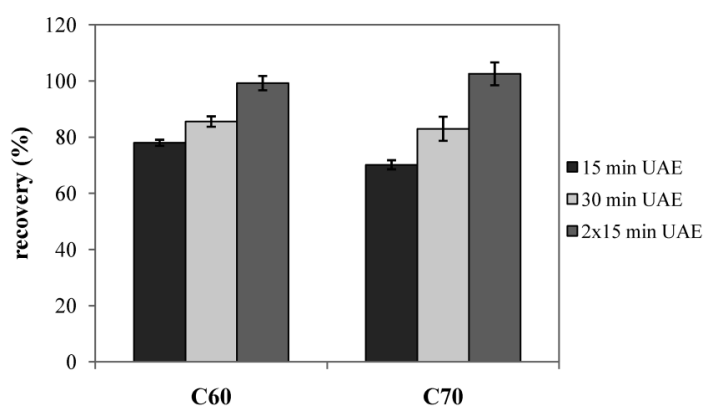

Fig. 3 Effect of the number and time of the sonication cycles in the recoveries of $\mathrm{C} 60$ and $\mathrm{C} 70$ by UAE.

method.

Given that $\mathrm{C} 60$ is prone to degradation when solutions are stored in light conditions, extractions were performed without light exposure, protecting the columns and tubes with aluminum foil, and using amber vials in the chromatographic analysis to avoid a potential photodecomposition of the analytes.

The extractive solvent is usually one of the parameters used to optimize in UAE methods. Various solvents are usually evaluated in order to cover a wide range of polarity. Nevertheless, due to the poor solubility of fullerenes in most organic solvents, only toluene was used in the extractive process. Temperature is one of the main factors evaluated in the extraction of organic compounds from solid environmental matrices because high temperatures usually improve analyte extraction. However, it has been reported that C60 exhibits an anomalous solubilitytemperature trend, because the temperature of maximum C60 solubility ranges from 3 to $37^{\circ} \mathrm{C}$ depending on the solvent. ${ }^{4}$ In our work, the effect of two extraction temperatures (22 and $37^{\circ} \mathrm{C}$ ) on the recoveries by UAE of C60 and C70 in soil samples spiked at the lowest assayed level $(2 \mathrm{ng} / \mathrm{g})$ was evaluated. It was observed that at $37^{\circ} \mathrm{C}$ the recovery of $\mathrm{C} 60$ decreased (around $44 \%$ ), whereas the extraction yield of C70 did not improve (Table 1). Thus, an extraction temperature of $22^{\circ} \mathrm{C}$ (room temperature) was selected for further experiments.

The number and time of the sonication cycles were also assayed using the same total volume of extraction solvent $(8 \mathrm{~mL})$. Thus, the recoveries obtained with a single cycle of 15 or 30 min and with two cycles of 15 min are shown in Fig. 3. The use of a $2 \times 15$ min cycles of ultrasonic extraction with $4 \mathrm{~mL}$ of toluene each time improved the extraction efficiency of both fullerenes. From the obtained results, it was concluded that fullerenes can be successfully extracted from soil samples placed in small column by UAE with toluene, at room temperature and using two cycles of $15 \mathrm{~min}$ with $4 \mathrm{~mL}$ of extraction solvent each time.

The effect of soil moisture on the recovery of fullerenes was evaluated by adding $0.75 \mathrm{~mL}$ of water to soil samples previously fortified at $200 \mathrm{ng} / \mathrm{g}$ and maintained in darkness for $24 \mathrm{~h}$. It has
Table 2 Effect of moisture in the recoveries ${ }^{\mathrm{a}}(\% \pm \mathrm{SD})$ of C60 and C70 (200 ng/g) from soil

\begin{tabular}{ccccc}
\hline \multirow{2}{*}{ Compound } & Air-dried soil & & \multicolumn{2}{c}{ Moist soil (15\%) } \\
\cline { 2 - 2 } \cline { 4 - 4 } & UAE & & UAE & Percolation + UAE \\
\hline C60 & $100.0 \pm 2.5$ & & $1.2 \pm 0.1$ & $89.0 \pm 1.5$ \\
C70 & $103.7 \pm 4.1$ & & $1.5 \pm 0.3$ & $89.6 \pm 2.3$ \\
\hline
\end{tabular}

a. Number of replicates, $n=4$.

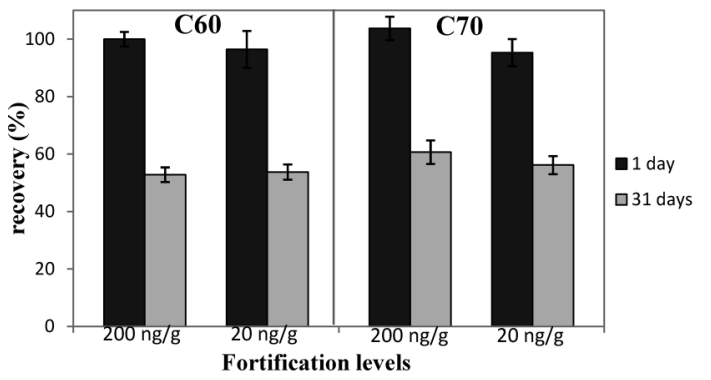

Fig. 4 Recoveries of C60 and C70 one day after spiking or after an aging period in soil of 31 days.

been described that soil moisture has a high influence on the recovery of $\mathrm{C} 60 .{ }^{11}$ The effect of a $15 \%$ moisture content resulted in a drastic decrease in the extraction yield of C60 and C70 from soil applying UAE; thus, very low recoveries were obtained for C60 and C70 (Table 2). The use of a vacuum manifold for $60 \mathrm{~min}$ to dry the soil column before the extraction step, did not improve the recoveries probably due to water remaining in the soil pores. However, high recoveries for C60 and $\mathrm{C} 70$ were obtained when $6 \mathrm{~mL}$ of $\mathrm{ACN}$, a solvent with a low C60 solubility, ${ }^{12,13}$ were percolated through the column before performing UAE (Table 2). Thus, $\mathrm{C} 60$ and $\mathrm{C} 70$ could be extracted from wet soils with only a $10 \%$ decrease in their recovery. According to this, after a quick and easy preliminary step, the UAE method allowed to extract wet samples with good recoveries.

The effect of the aging of residues in soil on the extraction behavior of C60 and C70 fullerenes was also considered in this work by evaluating the recovery of fullerenes one month after spiking soil samples at two concentration levels (200 and $20 \mathrm{ng} / \mathrm{g}$ ). In comparison with freshly spiked soil samples, the extraction of aged residues resulted in lower recoveries (Fig. 4); although these recoveries are similar to those reported by Shareef et al. ${ }^{11}$ for $\mathrm{C} 60$ after an aging period in soil of 32 days (with recoveries from 58 to $64 \%$ ). Nevertheless, it is necessary to point out that they used a high concentration of C60 (1 mg/ $\mathrm{kg}$ ) in the assay, and that its recovery after 1 day was lower than those obtained in our work at much lower concentration levels $(0.2$ and $0.02 \mathrm{mg} / \mathrm{kg})$.

\section{Comparison of UAE and PLE procedures}

For comparative purposes, the results obtained by UAE for the extraction of $\mathrm{C} 60$ and $\mathrm{C} 70$ fullerenes in soil were compared with those obtained by PLE. In this study, soil extraction by PLE was carried out following a method proposed by Shareef et al. ${ }^{11}$ with slight modifications. Temperature was the main extraction parameter, which differs between our PLE system and the system used in the reported method (Dionex ASE system), mainly due to the different geometry and the principle 
of their heating systems. Accordingly, the influence of the temperature on the extraction by PLE of C60 and C70 in soil at two concentrations ( 20 and $2 \mathrm{ng} / \mathrm{g}$ ) was evaluated at 30, 60, 90 and $120^{\circ} \mathrm{C}$. Obtained results showed that there was an effect of temperature on the recoveries, mainly at low concentrations. Thus, there were significant differences between the recoveries of fullerenes by PLE at different temperatures for $2 \mathrm{ng} / \mathrm{g}$ spiking level (Fig. 5). Lower recoveries were obtained at $30^{\circ} \mathrm{C}$; however, the best results were obtained at 90 and $120^{\circ} \mathrm{C}$.

Figure 5 shows a graphical comparison of the extraction efficiencies of both techniques. Higher recovery values for C60 and C70 were obtained by UAE than by PLE. The results obtained by PLE for C60 were of the same order as those reported by Shareef $e t$ al. ${ }^{11}$

In addition, several parameters, such as the volume of organic solvent, the time of analysis, equipment needed or fullerene recoveries were considered in order to perform comparisons of both extraction procedures. Thus, concerning the solvent consumption, UAE used a lower volume than PLE $(9.5 \mathrm{~mL}$ and around $28 \mathrm{~mL}$ for UAE and PLE, respectively). Furthermore, extracts were collected and concentrated directly in graduated tubes in the UAE method; however, the extracts obtained by PLE needed to be pre-concentrated and transferred to graduated tubes. Regarding the total time of analysis, both are quick
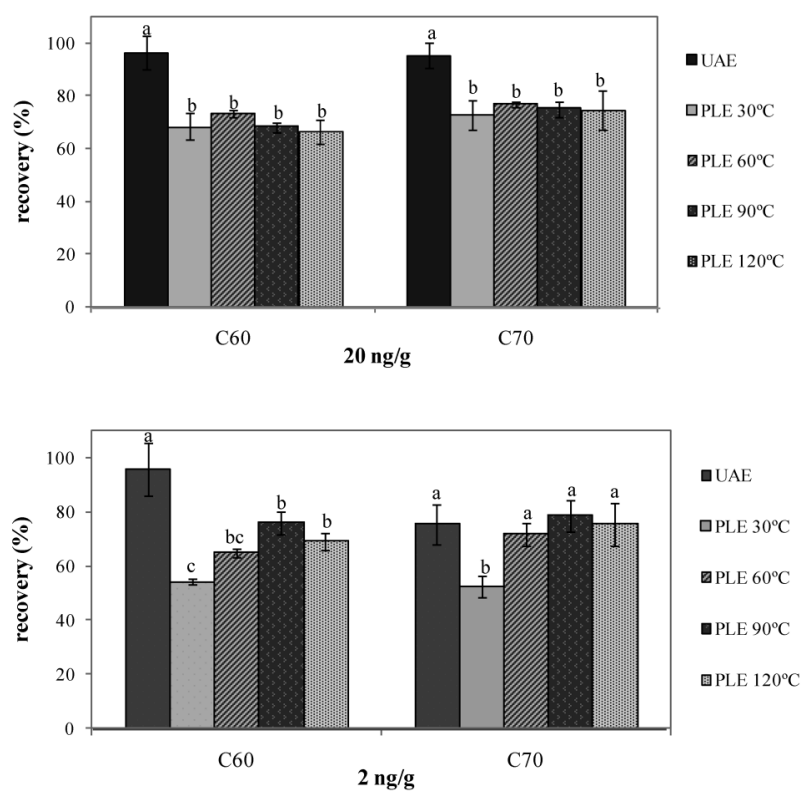

Fig. 5 Comparison of the relative recoveries of C60 and C70 obtained by UAE and PLE (at 30, 60, 90 and $120^{\circ} \mathrm{C}$ ) at two fortification levels. Means with different letters are significantly different $(p=$ $0.05)$. extractive procedures that allow performing various samples simultaneously (six by PLE and twelve by UAE). In the case of UAE, a simple percolation with ACN of the soil column allowed good recoveries for wet samples; whereas, a freeze drying step was described as necessary before PLE. ${ }^{11}$ Finally, another drawback of the PLE method is the sophisticated extraction instrumentation required, whereas the UAE method does not need any special laboratory equipment to be carried out.

\section{Validation of the UAE method}

Extraction efficiencies obtained by UAE at different fortification levels assayed ranged from 78 to $104 \%$ (Table 3) with standard deviations $<10 \%$ for both fullerenes. Very good extraction efficiencies were obtained at high fortification levels, from 95 to $104 \%$ for both compounds; however, the recoveries of C70 were lower at the lowest fortification level $(75.5 \%)$. Shareef et al. ${ }^{11}$ reported recoveries of $\mathrm{C} 60$ in soil lower than $75 \%$, and Wang et al. ${ }^{5}$ obtained recoveries from 86 to $99 \%$ at concentrations between 1620 and $320 \mathrm{ng} / \mathrm{g}$ in dry sediment. No data has been found in the available literature regarding the recovery of $\mathrm{C} 70$ from soil or sediments. In general, the recoveries of $\mathrm{C} 70$ obtained by UAE for these matrices were quite similar to those obtained for C60 (Table 3).

The LOQs for the developed method were $0.9 \mathrm{ng} / \mathrm{g}$ for both fullerenes in soil and slightly lower in sediments $(0.7$ and $0.8 \mathrm{ng} / \mathrm{g}$ for C60 and C70, respectively). The LOQs obtained with this method were lower than those reported by other authors, with values of $20 \mathrm{ng} / \mathrm{g}$ for C60 in soil by PLE ${ }^{11}$ or $150 \mathrm{ng} / \mathrm{g}$ for C60 in artificial sediment by shaking extraction. ${ }^{5}$ In the case of other matrices, LOQ values from 0.2 to $1 \mathrm{ng} / \mathrm{L}$ were reported for C60 and C70 in the effluents of wastewater treatment plants. ${ }^{15}$

A multipoint calibration curve was obtained after injecting nine calibration standards solutions at different concentration. A good linearity was obtained in the range from 2.5 to $1000 \mu \mathrm{g} / \mathrm{L}$ with correlation coefficients equal to or higher than 0.9998 .

The repeatability of the chromatographic determination was determined by injecting 9 times a standard solution of $5 \mathrm{ng} / \mathrm{mL}$ with an automatic injector. The relative standard deviations (RSD) obtained for retention times were $<0.04 \%$ and RSD of peak areas ranged from 5 to $7 \%$. The within-laboratory reproducibility of the chromatographic determination was evaluated during different days, and was found to be lower than $12 \%$ for both compounds, expressed as RSD.

The specificity of the proposed method was assessed by analyzing blank soil samples. The absence of background peaks at the retention times of the compounds showed that no interferences occurred.

\section{Application to real samples}

The validated UAE method was applied to the determination of fullerenes in six agricultural and three industrial soil samples,

Table 3 Recoveries ${ }^{\mathrm{a}}(\% \pm \mathrm{SD})$ of the studied fullerenes in soil and sediment obtained by UAE

\begin{tabular}{cccccccr}
\hline & \multicolumn{9}{c}{ Fortification levels (ng/g) } \\
\cline { 2 - 7 } Compound & \multicolumn{9}{c}{ Soil } & & \multicolumn{2}{c}{ Sediment } \\
\cline { 2 - 7 } & 200 & 100 & 20 & 2 & 20 & 2 \\
\hline C60 & $100.0 \pm 2.3$ & $95.4 \pm 4.9$ & $96.4 \pm 6.4$ & $95.5 \pm 9.8$ & $91.1 \pm 2.0$ & $72.2 \pm 6.3$ \\
C70 & $103.7 \pm 4.1$ & $99.6 \pm 3.0$ & $95.3 \pm 4.8$ & $75.5 \pm 7.3$ & $91.6 \pm 4.6$ & $78.8 \pm 9.8$ \\
\hline
\end{tabular}

a. Number of replicates, $n=4$. 
as well as in five sediment samples. C60 and C70 were not detected in any of the analyzed samples. It should be remarked about the scarcity of information available regarding these emerging contaminants in the environment.

However, the broad use of these compounds in commercial products, together with an expected increase of their industrial applications and household usages, will certainly increase the potential presence of these compounds in the environment; ${ }^{23}$ thus, it is necessary to develop adequate analytical methods for the determination of these compounds in environmental samples.

\section{Conclusions}

A rapid, simple and sensitive method, based on the UAE of samples placed in small columns, has been developed for the determination of $\mathrm{C} 60$ and $\mathrm{C} 70$ fullerenes in soil and sediments by HPLC-UV. With the proposed method, extractions were performed with a low volume of solvent allowing the determination of these compounds in complex matrices, without the need of a previous sample preparation or sophisticated extraction instrumentation. High extraction efficiencies were obtained for both fullerenes at the different fortification levels evaluated. The use of a small volume of ACN previously to UAE, allowed obtaining high recoveries for C60 and C70 with wet samples and without the need of a previous freeze-drying step. In comparison with freshly spiked soils, a decrease in the recovery rates was observed with aged samples. The LOQs obtained for both fullerenes were lower than those reported for by other authors with similar matrices, using HPLC-UV. The main advantages of the UAE method, in comparison with the PLE procedure, were the higher recoveries obtained without requiring special equipment to carry out the extractions. Finally, the UAE method was applied to the analysis of fullerenes in soil and sediment samples collected in various areas of Spain and in different rivers of Madrid, however, no fullerene residues were found in these samples.

\section{Acknowledgements}

This study was financed by the Ministry of Science and Innovation-National Institute for Agricultural and Food Research and Technology, INIA, Project number "RTA 2011-00047-0000 ".

\section{References}

1. X. Ma, J. Geiser-Lee, Y. Deng, and A. Kolmakov, Sci. Total
Environ., 2010, 408, 3053.

2. Norwegian Pollution Control Authority, "Environmental fate and ecotoxicity of engineered nanoparticles. Report no. TA 2304/2007', ed. E. J. Joner, T. Hartnik, and C. E. Amundsen, 2008, Bioforsk.

3. J. Jehlička, O. Frank, V. Hamplová, Z Pokorná, L. Juha, A. Boháček, and Z. Weishauptová, Carbon, 2005, 43, 1909.

4. C. W. Isaacson, M. Kleber, and J. A. Field, Environ. Sci. Technol., 2009, 43, 6463.

5. C. Wang, C. Shang, and P. Westerhoff, Chemosphere, 2010, 80,334

6. J. Sanchís, N. Berrojalbiz, G. Caballero, J. Dachs, M. Farré, and D. Barceló, Environ. Sci. Technol., 2012, 46, 1335.

7. B. F. G. Pycke, T. M. Benn, P. Herckes, P. Westerhoff, and R. U. Halden, TrAC, Trends Anal. Chem., 2011, 30, 44.

8. USEPA, 2009, Emerging Contaminants-Nanomaterials. Fact Sheet, http://clu-in.org/emergingcontaminants/.

9. P. Vítek, J. Jehlička, O. Frank, V. Hamplová, Z. Pokorná, L. Juha, and Z. Boháček, Fullerenes, Nanotubes, Carbon Nanostruct., 2009, 17, 109.

10. J. Wang, Q. Cai, Y. Fang, T. A. Anderson, and G. P. Cobb, Talanta, 2011, 87, 35.

11. A. Shareef, L. Guihua, and R. S. Kookana, Environ. Chem., 2010, 7, 292.

12. Y. Q. Wu, Y. L. Sun, Z. N. Gu, Q. W. Wang, X. H. Zhou, Y. Xiong, and Z. X. J. Jin, J. Chromatogr., A, 1993, 648, 491.

13. R. S. Ruoff, D. S. Tse, R. Malhotra, and D. C. Lorents, J. Phys. Chem., 1993, 97, 3379.

14. N. Sivaraman, R. Dhamodaran, I. Kaliappan, T. G. Srinivasan, P. R. P. Vasudeva Rao, and C. K. C. Mathews, Fullerene Sci. Technol., 1994, 2, 233.

15. M. Farré, J. Sanchís, and D. Barceló, J. Hydrol., 2010, 383, 44.

16. R. Kubota, M. Tahara, K. Shimizu, N. Sugimoto, A. Hirose, and T. Nishimura, Toxicol. Lett., 2011, 206, 172.

17. D. Bouchard and X. Ma, J. Chromatogr., A, 2008, 1203, 153.

18. S.-R. Chae, E. M. Hotze, Y. Xiao, J. Rose, and M. R. Wiesner, Environ. Eng. Sci., 2010, 27, 797.

19. Y. Xiao, S.-R. Chae, and M. R. Wiesner, Chem. Eng. J., 2011, 170, 555.

20. J. R. Deye, A. N. Shiveley, S. A. Oehrle, and K. A. Walters, J. Chromatogr., A, 2008, 1181, 159.

21. T. M. Benn, P. Westerhoff, and P. Herckes, Environ. Pollut., 2011, 159, 1334.

22. J. L. Tadeo, C. Sánchez-Brunete, B. Albero, and A. I. García Valcárcel, J. Chromatogr., A, 2010, 1217, 2415.

23. S. T. Mukherji, J. Leisen, and J. B. Hughes, Chemosphere, 2011, 84, 390. 